\title{
WIP: Mentoring Early-career Engineering Faculty - A Faculty Development Coordinator Model
}

\section{Dr. Julie Walters, Oakland University}

Julie Walters, J.D., Ph.D. Is an associate professor in the Department of Political Science at Oakland University, Rochester, Michigan. Her research and teaching address issues of law and public policy in the United States, particularly in the context of institutional and cultural dynamics. Recent work focuses on legal and normative issues surrounding the employment environment of women in STEM.

\section{Miss Leanne DeVreugd, Oakland University}

Leanne DeVreugd is the Program Coordinator for the Women in Science, Engineering, and Research Program (WISER) and other faculty development initiatives of the Research Office at Oakland University. She received both her undergraduate and graduate degrees from Oakland University, completing her Master's of Public Administration in 2011 and post-Master's certificate in Human Resources Management in 2017.

\section{Dr. Laila Guessous, Oakland University}

Laila Guessous, $\mathrm{Ph}$.D. is a professor in the department of mechanical engineering at Oakland University (OU) in Rochester, MI. Her research and teaching interests lie in the areas of fluid mechanics and heat transfer, with an emphasis on computational methods. She is the program director for the NSF-funded AERIM REU program at OU, and was a co-PI on the Oakland University WISE@OU NSF ADVANCE Partnerships for Adaptation, Implementation, and Dissemination (PAID) grant. 


\section{WIP - Mentoring Early-career Engineering Faculty: A Faculty Development Coordinator Model}

\section{Introduction}

The benefits that flow to both early career faculty mentees and their academic institutions from mentoring activities continues to be well documented [1] [2]. Research productivity, teaching skills, and service contributions are common factors by which a new faculty member will be assessed on the path to promotion. Yet navigating one's department and the larger institutional environment in light of these factors while maintaining a healthy work/life balance can be daunting. At the same time, failure to successfully navigate one or more of these areas can lead to professional and personal disappointments with lasting impacts, hence the importance of building a knowledge base on effective faculty mentoring.

To contribute to the faculty mentoring model knowledge base, this work-in-progress paper details the objectives, structure, and implementation of a mentoring model for new faculty in a school of engineering and computer science (SECS) following its host institution's (Oakland University, OU) receipt of an NSF ADVANCE Partnerships for Adaptation, Implementation, and Dissemination (PAID) grant between 2011 and 2016.

While informal and ad-hoc mentoring of early and mid-career STEM faculty was taking place in some instances, a majority of female and male STEM faculty indicated the need for more mentoring, particularly in the area of research. One important goal for the WISE@OU leadership team was hence to help encourage a culture of mentorship within the STEM departments so that more senior faculty would get involved and the value of mentorship both to the mentee and to the mentor would be recognized.

The SECS undertook efforts to develop mentoring activities for its early career faculty. A mentoring model adopted by it involves the use of a Faculty Development Coordinator (FDC) who serves as a point person for untenured (and often tenured) faculty within the School. The FDC follows a "mentor network" model, serving as a facilitator who can connect faculty with others who may be better able to help with a specific issue. The FDC also provides one-on-one mentoring and organizes several group activities. While this faculty mentoring program is still evolving, this paper describes the setup of the FDC mentoring model in the SECS and presents some preliminary assessment data based on faculty survey responses.

\section{The SECS Mentoring Model: Fundamentals}

The eventual adoption of a Faculty Development Coordinator (FDC) model for mentoring in the SECS was the culmination of several years of consideration of competing models. Little research exists regarding faculty mentoring in engineering programs and the eventual choice of a form of network mentoring was informed by a review of the literature in multiple fields as well as experiential knowledge of members of the WISE@OU and SECS program's leadership team.

Decision makers on the matter recognized that new faculty have diverse needs and the SECS would need a mentoring model that provided for flexibility in meeting those needs. This observation is very much in line with the work of K.A. Rocquemore who has found that it is normal for early career faculty to vary in need across a range of areas such as professional development, emotional support, intellectual community, role models, safe spaces, accountability for what really matters, sponsorship, access to opportunities, and substantive feedback.[3] 
In the end, network-based mentoring appeared to provide the best general structure for crafting the School's mentoring initiative. A key strength of network-based mentoring includes the move away from what is often termed "the guru model," in which a single person is expected to address all of the needs of the mentee, to a diversified structure in which those with expertise in one of the areas of need are part of the program (whether formally or informally).

The FDC serves as a point person for untenured faculty within the SECS. The FDC model involves the structural elements described below. The coordinator:

- reaches out to all newly hired faculty as soon as provided with their contact information by department Chairs.

- meets individually with new faculty; provides information that they may need when they first arrive at OU.

- $\quad$ organizes on average monthly/bi-weekly formal and informal group sessions for untenured faculty throughout the year. Formal meetings focus on topics such as tenure/promotion, teaching issues; informal ones are more social. Typical attendance ranges from $15 \%$ to $75 \%$ of the untenured faculty in SECS. These would be in addition to any workshops organized by the OU Center for Excellence in Teaching and Learning or by the OU Research Office.

- meets with early career faculty one-on-one either at their request or initiated by the FDC if a faculty member seems to be struggling with an issue. These include promotion/tenure information meetings. Typically, the FDC has one or more one-on-one meetings per week.

- offers to review grant proposal drafts or to help identify other faculty willing to do so. This activity has decreased over the past year after the hiring of a research development officer.

- $\quad$ serves as a facilitator who can connect faculty with others who may be better able to help with a specific issue, such as childcare options and medical issues requiring leave.

Under the FDC model, the coordinator receives some summer compensation and one course release (usually in the Fall) to undertake this service.

\section{Phase 1 Data Collection: The Survey Instrument}

During the fall of 2019, the authors began developing the survey instrument to be used in the first phase of data collection aimed at assessing the FDC model's success at meeting mentoring objectives. Qualtrics software was chosen to facilitate the survey principally as the authors had experience using it in other academic contexts and in particular with the climate survey they were involved as members of the NSF ADVANCE PAID grant leadership team.

The questions in the survey had two foci. First, we wanted to assess the SECS's early career faculty members' satisfaction with the FDC in light of the position's responsibilities. The second focus was to assess common mentoring needs in relation to the availability of- and satisfaction with- related resources outside their (respondents) experience with the FDC (e.g., their departments, the SECS overall, the university). The survey invitation was emailed to 24 early career (untenured) faculty members who had been hired in the past 5 years. Prospective respondents were assured that their answers would be both anonymous and confidential.

\section{Preliminary Findings and Implications}

The survey had a participation rate of $91.6 \%$. All respondents $(100 \%)$ had met one-on-one with the FDC. This would be expected as meeting with new hires in person within a short time of their being hired is a responsibility of the coordinator, as mentioned above. 
Respondents were then asked their satisfaction rating with that experience in the context of the nine (9) categories. The categories included: tenure/promotion, research, working with students, work/life balance, setting up a research lab, navigating department politics, teaching guidance, service, other. Respondents were given an opportunity to type their explanation/comment regarding their answers. A Likert scale of 1-5 was provided regarding satisfaction (1: Very Dissatisfied; 2: Somewhat Dissatisfied; 3: Neither Dissatisfied or Satisfied; 4: Somewhat Satisfied; 5: Very Satisfied).

\begin{tabular}{|c|c|c|}
\hline \multicolumn{3}{|c|}{$\begin{array}{l}\text { Table 1: Summary of responses to one-on-one and } \\
\text { group meetings (scale 1-5) }\end{array}$} \\
\hline \multirow[t]{2}{*}{ Category } & \multicolumn{2}{|c|}{ Average rating } \\
\hline & One-on-one & Group meetings \\
\hline Tenure/Promotion & 4.6 & 4.6 \\
\hline Research & 4.4 & 4.4 \\
\hline Working with Students & 4.6 & 4.5 \\
\hline Work/Life Balance & 4.8 & 4.5 \\
\hline Setting up Research Lab & 4.1 & 4.0 \\
\hline Navigating Dept. Politics & 4.2 & 4.4 \\
\hline Teaching Guidance & 4.8 & 4.7 \\
\hline Service & 4.6 & 4.7 \\
\hline Other & 4.5 & 4.8 \\
\hline \multicolumn{3}{|c|}{$\begin{array}{l}+ \text { [ ] did a great job for junior faculty members like me. In } \\
\text { addition to one-on-one in person lunch meetings, [ ] was } \\
\text { very responsive and quick to answer my email questions. } \\
\text { We are very lucky to have [ ]! } \\
+ \text { I think that [ ] does a fabulous job. However, mentoring } \\
\text { everyone untenured is far too much for one person. In } \\
\text { addition, things like department politics vary within } \\
\text { individual departments, and [ ] is just in one department, } \\
\text { so there are certain things that [ ] cannot advise people } \\
\text { about outside of [ ] department. }\end{array}$} \\
\hline
\end{tabular}

Table 1 summarizes the ratings averages in all nine categories for one-on-one and group meeting contacts with the FDC. While few respondents provided comments, those that did gave high praise of the FDC praising the coordinator's work as "exceptional" and characterizing the individual as an "absolute treasure." The remaining two comments were also highly complementary and provided somewhat more detail (identifying details removed).

Of particular importance is the observation by the respondent that politics vary within individual departments and that the FDC is limited in ability to truly understand the nuances of such politics. This is a reality the FDC recognizes and it highlights the importance of the existence of senior faculty in other departments to provide confidential guidance of this nature. In sum, it appears that early career faculty in School SECS are somewhat to highly satisfied with the FDC in all categories, both in one-on-one and group contexts. It appears that early career faculty in the SECS are benefiting from the FDC's work.

We also wanted to ask similar questions about support outside of the FDC since the FDC is not expected to be the sole mentor to early career faculty in all departments (Table 2). Indeed, one

\begin{tabular}{|l|l|l|l|}
\hline \multicolumn{3}{|c|}{$\begin{array}{c}\text { Table 2: Summary of responses to degree of support from } \\
\text { different institutional levels (scale 1-4) }\end{array}$} \\
\hline \multirow{2}{*}{ Category } & \multicolumn{3}{|c|}{ Average rating } \\
\cline { 2 - 4 } & Department & SECS & OU \\
\hline Tenure / Promotion & 3.13 & 3.36 & 2.50 \\
\hline Research & 3.00 & 2.80 & 2.93 \\
\hline Working with students & 3.40 & 2.93 & 2.71 \\
\hline Work/Life balance & 3.00 & 2.79 & 2.62 \\
\hline Setting up research lab & 2.80 & 2.57 & 2.15 \\
\hline Navigating department politics & 2.87 & 2.62 & 2.00 \\
\hline Teaching guidance & 3.20 & 2.85 & 3.00 \\
\hline Service & 3.33 & 2.93 & 2.71 \\
\hline Other & 2.90 & 2.50 & 2.13 \\
\hline
\end{tabular}

person cannot do it all regarding such support.[4] Hence it is important that support exists outside of the FDC's role. We asked a question regarding perceived degree of support in the respondent's own department, SECS and university (OU) regarding the nine (9) categories mentioned previously. Here a scale of $1-$ 4 was used (1: no support; 2 : limited support, 3: adequate support and 4: strong support.)

Three (3) categories revealed average scores less than the measure of adequate 
support at all three levels. They included research lab set up, navigating department politics, and other. Regarding "other," no respondent provided feedback in the comment opportunity to help us understand how they interpreted the "other" option. This would be a candidate for further examination via focus groups. At the school level, though on average respondents found that the SECS provides adequate support regarding tenure and promotion, the remaining categories evidenced an average assessment between "adequate" and "limited support."

At the institutional level (outside of respondents' departments and the SECS), the satisfaction average for eight (8) of the nine (9) categories was between limited and adequate "limited support" with the categories of teaching and research receiving the highest ratings, which we attribute to the existence of dedicated units focused on assisting faculty with these activities. The two comments we received in conjunction with this question were,

- In general, there is a lot of support around here and people are very willing to provide guidance and recommendations on things, especially if you seek it out and ask.

- The support provided at the level of department, school (SECS) and university is strong and very satisfactory.

Of note is the first comment which draws attention to the need for early career faculty to reach out. Such motivation on the part of the faculty members is an important partner to any institutional level that provides support resources and ensures there are no obstacles to accessing the resources. Nevertheless, a focus group investigation of the responses from this question should be able to provide more perspective on the response-averages in all categories.

\section{Conclusion: Planning Phase 2 Assessment}

Our next phase of data collection will involve at least one focus group meeting in which the facilitator will be a OU faculty member in social sciences. The aim of the focus group meeting will be to provide the early career faculty of the SECS an opportunity to share feedback surrounding the survey questions using an in-person context. In this way, they will have the anonymity and confidentiality they had with the online survey but will be able to elucidate their thoughts verbally on issues related to the questions of the survey. Though we were pleased with the overall high return rate on our survey $(91.6 \%)$ the small amount of commentary from respondents does indicate the need for a focus group follow up. We also aim to explore responses to some of our questions (not shown here) that pertain to sense of isolation or comfort expressing opinions at the department level.

\section{References}

1. Trower, C. A. (2012). Success on the Tenure Track: Five Keys to Faculty Job Satisfaction. Baltimore, MD: The Johns Hopkins University Press.

2. Hoffman, L., Aubrey, R.A., \& Taylor, K.D. (1998). Mentoring for Success. American Society for Engineering Education Annual Conference Proceedings, 1998. Washington, DC: American Society for Engineering Education.

3. Rockquemore, K.A. (2013). A New Model of Mentoring, Inside Higher Ed, https://www.insidehighered.com/advice/2013/07/22/essay-calling-senior-faculty-embracenew-style-mentoring.

4. Rocquemore, K.A. (2013). Be a Coach, Not a Guru, Inside Higher Ed, https://www.insidehighered.com/advice/2013/07/29/essay-coaching-style-mentoring. 